\title{
The adoption of robotics in the auditing profession
}

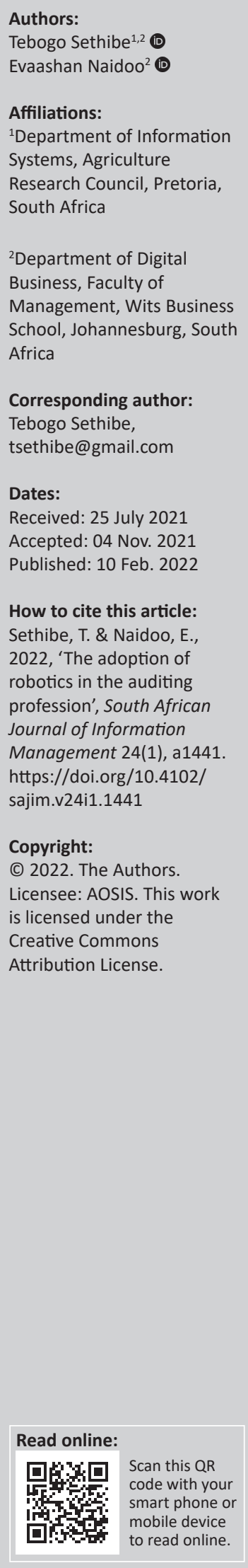

Background: The auditing profession has been burdened with high costs and reputational damage resulting from false results because of a high dependency on manual tasks susceptible to errors or manipulation. Automating repetitive tasks with the use of robots can help minimise these errors to achieve efficiencies and cost reduction.

Objectives: This study adopted a Unified Theory of Acceptance and Use of Technology (UTAUT) model to determine the factors influencing organisations to use robotics technology when performing auditing activities.

Methods: The study was quantitative, using a survey consisting of 37 questionnaires and two semi-structured interview questions. The sample consisted of 59 professional auditors and 26 non-auditors involved in auditing in South Africa.

Results: The study results show that performance expectancy and facilitating conditions are key factors that influence the adoption of robotics in the auditing profession. A lack of training, data quality, and inadequate investment in robotics technology are mentioned as critical barriers to adopting robotics in auditing. Management support, good change management processes and technology skills are quoted as potential key enablers of robotics technology in the auditing profession.

Conclusion: The conclusion drawn from the study is twofold. Firstly, the performance management system and the business case for robotics in the auditing process should be linked to the tasks of auditors. Secondly, resources should be made available to support the use of technology in the profession. The study provides more insight into how leaders and management in the auditing profession could influence the adoption of robotics in auditing.

Keywords: adoption, auditing, automation, robots, technology acceptance model, theory of planned behaviour, theory of reasoned action, unified theory of acceptance, use of technology.

\section{Introduction}

Increasingly, competitive advantage is driven by organisations' abilities to access, collect, synthesise, analyse, and exploit insights from data (Rose, Rojhani \& Rodriques 2018). As a result, big data and data science have experienced unprecedented growth in recent years (Tang, Norman \& Vendrzyk 2017). This ongoing technological advancement presents challenges and opportunities for auditing professionals and the profession (Tiberius \& Hirth 2019). For internal auditors, the challenge is how the profession can help businesses understand, codify, and develop appropriate controls around the new risk presented by the advancement of these technologies (Rose et al. 2018). By the same token, as an increasing amount of data becomes available, organisations seek avenues to exploit data for insights, efficiencies, and competitive advantage (Sharma, Mithas \& Kankanhalli 2014). According to the Auditor General of South Africa (2011), an organisation is issued with a clean audit outcome when there is evidence that its financial statements are free from material misstatement and there are no material findings on the reporting of performance objectives or noncompliance with legislation. As such, the role of internal auditors is to determine what the organisation is doing to ensure effective governance of its processes and systems (Rose et al. 2018).

\section{Problem statement and motivation}

Public accounting firms actively consider emerging technologies such as robotic process automation (RPA) when developing future software audit tools to improve efficiencies (Harris 2017). Robotic process automation is preconfigured software that executes a combination of processes, activities, transactions, and tasks to automate tasks that have structured data, rulebased processes, and a single, correct outcome (Lacity \& Willcocks 2016). From an auditing perspective, robotics can be used to perform routine activities such as carrying client's data from 
prior years within the accounting firm's audit platform, and testing of the benefits plan, to mention but a few (Cooper et al. 2019; Huang 2018). Despite the importance of using data analytics and robotics in audit engagements to improve audit quality and practical needs for leveraging big data to gain insights, the use of technology in audit engagement is still limited (Wang \& Cuthbertson 2015). The purpose of this study was to examine auditors' perceptions on adopting robotics in the auditing profession.

\section{Literature review}

\section{Auditing}

According to Seago (2017), auditing is an assessment of the organisation's controls that have been implemented for resource allocation, making provision for evaluating opportunities and protecting the organisation from risk. From a financial perspective, auditing provides assurance of financial performance and the non-financial risk position of an organisation (Gurama, Usman \& Murtala 2019). Auditing provides independent assurances to investors with reliable information on the financial status of an organisation to assist in financial decision-making (Hermanson, Hermanson \& Hermanson 2020). As such, an auditor's role is primarily to detect fraudulent or dishonest events that could affect the financial reporting of financial status (Ajao, Jayeoba \& Ajibade 2016). External auditing focuses on analysing and validating processes or records to provide an independent opinion on an organisation's financial position (Sexton \& Rudman 2019). In contrast, internal auditing focusses on identifying areas of improving the efficiency or effectiveness of operational processes (Gurama et al. 2019).

\section{Robotics and automation}

The word 'robot' was derived from a Czech word 'robota', which translates into forced labour and has further evolved referring to dumb machines, machines that perform menial, repetitive tasks, and highly intelligent anthropomorphic robots of popular culture (Lanfranco et al. 2004). Robots operate through software that is able to interact with systems by imitating human actions to perform certain tasks (Syed et al. 2020). The use of robots has evolved from those used in factories to those with a higher degree of intelligence, such as providing professional services (Urban 2017). Robots can perform tasks from moving or assembling objects to providing customer and legal service, detecting medical conditions, detecting hazards in physical environments, and offering financial advisory services (Avery 2019; Cheng 2019; Hyken 2017; Lay 2019). With the above in mind, Kokina and Davenport (2019) argue that robotics decreases the time to complete tasks and the costs associated with processing data. This effectively improves the accuracy and consistency of the data and, in turn, results in better decisions. From an auditing perspective, robotics can enable auditors to automate repetitive tasks of extracting and preparing data to be tested so that auditors can channel their efforts on more value-added functions such as evaluating the quality and the accuracy of the data (Gotthardt et al. 2020; Lombardi, Bloch \& Vasarhelyi 2015).

\section{Prior studies on robotics and auditing}

Recent studies have attempted to demonstrate potential use cases for robotics technology in the auditing profession. For instance, Lois et al. (2020), using a sample of 105 participants from the largest audit institutions in Greece, conducted a study to examine continuous auditing in the digital age and the contemporary factors affecting continuous auditing. The study found that technological advances are indispensable for the establishment of an effective digital auditing system. The study further found that data protection measures, employee skills, and training are significant factors in continuous auditing.

In another study, Tiberius and Hirth (2019), using data collected from 177 participants, examined the changes in auditing practices that German auditing professionals expect within the next 5-10 years. The results of the study were threefold. Firstly, the results show that no far-reaching changes are expected in the near future; secondly, annual auditing will increasingly evolve toward continuous auditing, and thirdly, despite predominantly uncertain opinions, experts believe that new technologies will not replace auditors, but will rather provide relief and support in auditing.

Similarly, Tang et al. (2017) interviewed chief audit executives (CAEs) from six organisations across several industries to better understand the use of data analytics within the internal audit function (IAF) and the type of tools used. The study found that CAEs value professional certifications and the use of data analytics in the IAF. The CAEs indicated that they employed data analytics at different times and for various purposes. The most popular tools used to perform functions include creating reports that depict information graphically and show suspicious transactions, including Microsoft Excel, Microsoft Access, ACL, and Tableau.

\section{Unified Theory Acceptance and the Use of Technology Model}

Adapted from the Theory of Reasoned Action (TRA) and Technology Acceptance Model (TAM), the UTAUT model is the most commonly applied model for determining user intention to adopt technology (Venkatesh et al. 2003). It was formed through an integration of eight IT acceptance models that were used, specifically the TRA, the TAM, the Motivational Model, the Theory of Planned Behaviour (TPB), combined TAM and TPB, the Model of PC Utilisation, Social Cognitive Theory, and the Innovation Diffusion Theory. The UTAUT model has several constructs that can be adjusted to suit scientific study. These constructs include performance expectancy, effort expectancy, social influence and facilitating conditions. Performance expectancy refers to the extent to which users believe that their work performance would be improved as a result of using the system. Effort expectancy denotes the degree to which users would use the system with minimal, or no additional effort required. Social influence is the extent to which individuals believe that those influential people, or important individuals, think that the individual should use the new technology. The facilitating conditions relate to an individual's belief that there is support in the organisation and technical infrastructure for using the system. 


\section{Research objectives and research hypothesis}

Following the literature, this study aimed to address the following primary research objectives (ROs):

- RO1: To determine the factors that could influence auditors to accept the use of robotics automation technology through the application of the UTAUT model:

- H1a: Performance expectancy has a positive and significant relationship with behavioural intention.

- H1b: Effort expectancy has a positive and significant relationship with behavioural intention.

- H1c: Social influence has a positive and significant relationship with behavioural intention.

- H1d: Performance expectancy has a positive and significant relationship with behavioural intention.

- RO2: To determine how these factors are influenced by age, gender and experience:

- H2: Age influences the relationship of all UTAUT constructs $(\mathrm{H} 2 \mathrm{a}=$ performance expectancy, $\mathrm{H} 2 \mathrm{~b}=$ effort expectancy, $\mathrm{H} 2 \mathrm{c}=$ social influence, and $\mathrm{H} 2 \mathrm{~d}=$ facilitating conditions) and behavioural intention.

- H3: Gender influences the relationship of all UTAUT constructs $(\mathrm{H} 3 \mathrm{a}=$ performance expectancy, $\mathrm{H} 3 \mathrm{~b}=$ effort expectancy, $\mathrm{H} 3 \mathrm{c}=$ social influence, and $\mathrm{H} 3 \mathrm{~d}=$ facilitating conditions) and behavioural intention.

- H4: Experience influences the relationship of all UTAUT constructs $(\mathrm{H} 4 \mathrm{a}=$ performance expectancy, $\mathrm{H} 4 \mathrm{~b}=$ effort expectancy, $\mathrm{H} 4 \mathrm{c}=$ social influence, and $\mathrm{H} 4 \mathrm{~d}=$ facilitating conditions) and behavioural intention.

- RO3: To determine the potential barriers for adopting robotics technology.

- RO4: To determine the potential enablers for using robotics automation in auditing in South Africa.

\section{Method}

A quantitative research strategy was adopted to investigate the potential use of robotics in the auditing profession. To enhance the richness of the study, a qualitative approach was employed to understand better the barriers and the enablers of adopting robotics in auditing activities.

\section{Sample and data collection}

A cross-sectional research design was adopted using questionnaires and semi-structured interview questions from 85 respondents representing various South African companies. The respondents were requested to complete the survey and to complete the interview questions online. Of the 154 respondents that were contacted, 94 responded and only 85 responses were usable. The majority of the respondents (56.5\%) were male, with $65.9 \%$ of the respondents under 40 years old. All the respondents held a diploma or a bachelor's degree, with 36.5\% holding an honour's degree and $28.2 \%$ having a master's degree as the highest qualification. Three $(3.5 \%)$ of the respondents held doctorate degrees. The majority of respondents $(67.1 \%)$ were internal auditors, whilst $30.6 \%$ were non-auditors. External auditors constituted $2.4 \%$ of the sample. The majority of respondents (78.8\%) were in the management category, with $63.4 \%$ had over 5 years of experience in the auditing profession. The overwhelming majority (98.8\%) knew of or had at least heard of the use of robotics in the workplace. Surprisingly, $60 \%$ of the respondents had a good understanding of the concept of robotics.

\section{Instruments and measures}

To assess the potential adoption of robotics on auditing (i.e. ROs 1 and 2), the questionnaires developed by Venkatesh et al. (2003) using UTAUT, were adapted and customised. Ultimately, the questionnaire consisted of 27 items in total, classified into five categories. These categories are performance expectancy (six items), effort expectancy (six items), social factors (seven items), facilitating conditions (five items) and behavioural intention (three items). Openended questions labelled 28 and 29 were added to gather the respondents' views on what the potential barriers and enablers of adopting robotics in auditing were.

\section{Data Analysis}

To answer ROs 1 and 2, correlation, Mann-Whitney U-Test, and regression analysis were used to examine the factors that could influence auditors to accept the use of robotics automation technology. For ROs 3 and 4, the analysis followed the six-phase process (familiarity with data, generation of initial codes, identification of themes, review themes, defining the themes and writing the report) for thematic analysis (Braun \& Clarke 2006).

\section{Data analysis and discussion}

To test the hypotheses, correlation and regression analyses were used to examine the nature of the relationship between behavioural intention and the UTAUT constructs. In this section, the descriptive statistics and correlation matrix results are presented, followed immediately by the results of the linear and moderated regression analysis. The section concludes with the thematic commentary on the barriers to and the enablers of robotics in auditing.

\section{Descriptive statistics and correlation}

In total, five constructs were included in this study; behavioural intention and four UTAUT constructs, namely, performance expectancy, effort expectancy, social factors and facilitating condition. Table 1 presents the means, standard deviations, Cronbach's alpha and correlation of all constructs included in the study. The constructs are listed by name in the first horizontal column and the abbreviation in the first vertical row.

Table 1 shows that all the reliability coefficients are well above the acceptance level of 0.70 . In addition, the results in Table 1 show that all UTAUT constructs relate positively to behavioural intention. From the individual analysis of the 
constructs for the UTAUT, it was clear that performance expectancy and social factors are moderate to high and has a strong positive relation with behavioural intention. As far as effort expectancy and facilitating conditions are concerned, the results show a moderate and strong positive relationship with behavioural intention.

\section{Mann-Whitney U-Test}

Because of the possible uneven distribution of auditor and nonauditor respondents in the sample, the Mann-Whitney U-Test was performed to assess any differences in the responses.

The results of the Mann-Whitney U-Test presented in Table 2 show no significant statistical differences $(p>0.05)$ between auditors and non-auditors for effort expectancy and facilitating conditions. In contrast, the result of the MannWhitney U-Test shows significant differences $(p<0.05)$ between the responses between auditors and non-auditors for behavioural intention, performance expectancy and social factors. Table 2 shows that the mean rank for auditors is higher for behavioural intention, performance expectancy

TABLE 1: Means, standard deviations, Cronbach's alpha and correlations.

\begin{tabular}{lccccccc}
\hline Variable & Mean & s.d. & BI & PE & EE & SF & FC \\
\hline $\begin{array}{l}\text { Behavioural } \\
\text { intention (BI) }\end{array}$ & 3.8588 & 0.76008 & $0.813^{\dagger}$ & - & - & - & - \\
$\begin{array}{l}\text { Performance } \\
\text { expectancy (PE) }\end{array}$ & 4.4196 & 0.55849 & $0.661 * *$ & $0.931 \dagger$ & - & - & - \\
$\begin{array}{l}\text { Effort expectancy } \\
\text { (EE) }\end{array}$ & 3.6196 & 0.66895 & $0.514^{* *}$ & $0.448^{* *}$ & $0.800 \dagger$ & - & - \\
$\begin{array}{l}\text { Social factors (SF) } \\
3.6924\end{array}$ & 0.66259 & $0.671^{* *}$ & $0.604^{* *}$ & $0.537^{* *}$ & $0.835 \dagger$ & - \\
$\begin{array}{l}\text { Facilitating } \\
\text { conditions (FC) }\end{array}$ & 3.4282 & 0.77715 & $0.549^{* *}$ & $0.361^{* *}$ & $0.558^{* *}$ & $0.578^{* *}$ & $0.813 \dagger$ \\
\hline
\end{tabular}

s.d., standard deviation.

$\dagger$, represent Cronbach alphas.

$*, p<0.05 ; * *, p<0.01$.

TABLE 2: Mann-Whitney U-Test.

\begin{tabular}{lclccc}
\hline Variable & $\boldsymbol{p}$ & Category & Number & Mean rank & Sum of ranks \\
\hline $\begin{array}{l}\text { Behavioural } \\
\text { intention }\end{array}$ & 0.021 & Auditor & 59 & 47.04 & 2775.50 \\
& & Non-auditor & 26 & 33.83 & 879.50 \\
Performance & 0.009 & Auditor & 59 & 47.53 & 2804.00 \\
expectancy & & Non-auditor & 26 & 32.73 & 851.00 \\
Effort & \multirow{2}{*}{0.969} & Auditor & 59 & 43.07 & 2541.00 \\
expectancy & & Non-auditor & 26 & 42.85 & 1114.00 \\
Social factors & \multirow{2}{*}{0.044} & Auditor & 59 & 46.56 & 2747.00 \\
& & Non-auditor & 26 & 34.92 & 908.00 \\
Facilitating & \multirow{2}{*}{0.646} & Auditor & 59 & 43.81 & 2585.00 \\
conditions & & Non-auditor & 26 & 41.15 & 1070.00 \\
\hline
\end{tabular}

and social factors, which suggest that auditors tend to agree more that performance expectancy and social factors have more impact on behavioural intention than effort expectancy and facilitating conditions.

\section{Regression analysis}

All hypotheses were tested using linear and moderated regression analyses, and the results are presented in Table 3. In general, the hypotheses are supported if the standardised beta coefficient (Beta) and coefficient (Coeff) have positive signs and are significant for linear and moderated regression, respectively.

The results of hypotheses H1a, H1b, H1c and H1d are presented in Model 1 (Table 3). From hypothesis H1a, we expected performance expectancy to have a positive effect on behavioural intention. In support of the hypothesis, the beta coefficient for performance expectancy and behavioural intention showed a significant positive impact $(\beta=0.432$, $p<0.01$ ), thereby indicating a strong positive relationship between performance expectancy and behavioural intention. Similarly, H4a predicted that facilitating conditions would have a positive effect on behavioural intention. Hypothesis H4a is supported $(\beta=0.312, p<0.01)$. In contrast, the results show no relationship between effort expectancy and social influence on behavioural intention. Therefore both hypothesis $\mathrm{H} 1 \mathrm{~b}$ and $\mathrm{H} 1 \mathrm{c}$ are rejected. In Model 2 (Table 3), the results of hypotheses $\mathrm{H} 2$ and sub-hypothesis $\mathrm{H} 2 \mathrm{a}$, $\mathrm{H} 2 \mathrm{~b}, \mathrm{H} 2 \mathrm{c}$ and $\mathrm{H} 2 \mathrm{~d}$ are presented. The hypothesis $\mathrm{H} 2$ stated that the relationship between all UTAUT constructs and behavioural intention construct is influenced by age. This hypothesis (H2) is rejected. The results show that subhypothesis H2c is supported (Coeff $=0.444, p<0.01$ ), thus indicating that the relationship between social influence and behavioural intention is moderated by age. In contrast, the results showed no significance $(p>0.01)$ when performance expectancy, effort expectancy and facilitating conditions were tested. Therefore, hypotheses $\mathrm{H} 2 \mathrm{a}, \mathrm{H} 2 \mathrm{~b}$ and $\mathrm{H} 1 \mathrm{~d}$ are all rejected.

Similarly, H3 in Model 3 (Table 3), asserted that all constructs of the UTAUT model and behavioural intention are influenced by gender, but this hypothesis is rejected. In fact, none of the UTAUT constructs were influenced by gender $(p>0.01)$. Therefore, sub-hypotheses H3a, H3b, H3c and H3d are rejected. Finally, Model 4 (Table 3) presents hypothesis

TABLE 3: Results of the linear and moderated regression analyses.

\begin{tabular}{|c|c|c|c|c|c|c|c|c|c|c|c|}
\hline \multirow[t]{3}{*}{ Variable } & \multirow{2}{*}{\multicolumn{2}{|c|}{ Model 1}} & \multicolumn{9}{|c|}{ Behavioural intention } \\
\hline & & & \multicolumn{3}{|c|}{ Model 2: Age } & \multicolumn{3}{|c|}{ Model 3: Gender } & \multicolumn{3}{|c|}{ Model 4: Exp } \\
\hline & Beta & $t$ & Coeff & $R^{2}$ & $t$ & Coeff & $R^{2}$ & $t$ & Coeff & $R^{2}$ & $t$ \\
\hline Performance expectancy & $0.432 * *$ & 4.789 & -0.087 & 0.475 & -0.361 & 0.128 & 0.474 & 0.568 & 0.375 & 0.537 & 0.998 \\
\hline Effort expectancy & 0.027 & 0.281 & 0.155 & 0.333 & 0.634 & 0.312 & 0.337 & 1.491 & -0.139 & 0.450 & -0.376 \\
\hline Social factors & 0.201 & 1.963 & $0.448 *$ & 0.473 & 1.984 & 0.25 & 0.467 & 1.345 & 0.093 & 0.512 & 0.342 \\
\hline Facilitating conditions & $0.312 * *$ & 3.470 & 0.131 & 0.358 & 0.721 & 0.306 & 0.423 & 1.793 & -0.017 & 0.458 & -0.072 \\
\hline Adjusted $R^{2}$ & 0.612 & - & - & & - & - & & - & - & & - \\
\hline
\end{tabular}

$* *, p<0.01 ; *, p<0.05$

exp, experience. 
$\mathrm{H} 4$ and sub-hypotheses H4a, H4b, H4c and H4d. Subhypotheses $\mathrm{H} 4 \mathrm{a}, \mathrm{H} 4 \mathrm{~b}, \mathrm{H} 4 \mathrm{c}$ and $\mathrm{H} 4 \mathrm{~d}$ tested the influence of experience on the relationship between each construct of the UTAUT model, namely performance expectancy, effort expectancy, social influence, and facilitating conditions and behavioural intention. The results were insignificant $(p>$ 0.01). Therefore, hypothesis H4 and sub-hypotheses H4a, $\mathrm{H} 4 \mathrm{~b}, \mathrm{H} 4 \mathrm{c}$ and $\mathrm{H} 4 \mathrm{~d}$ are all rejected.

\section{Thematic analysis}

The third and the fourth objectives of this research was to determine the potential barriers for adopting robotics technology and to determine the potential enablers for using robotics automation in auditing. The top-down approach was used to drive the analysis, which was driven by the RO. The study followed the five-phase process of thematic analysis developed by Braun and Clarke (2006). The findings reveal that a lack of management support, low technology skills, unavailability of good quality data, a lack of time for research and implementation of robotics, a lack of funding, and practical training are critical barriers for the adoption of robotics in the auditing profession. Other barriers that were mentioned included lack of trust, understanding, and culture. The training featured predominantly as the key enabler in ensuring the adoption of robotics, followed by the role that management plays in supporting the adoption. The respondents also highlighted that time was needed for the teams to experiment and learn to use the technology. Other themes such as the need to have access to the tools, focussing on efficiency gains, and having good change management processes, were also highlighted as factors that would be enablers for adopting robotics in auditing.

\section{Discussion}

This study investigated the impact of performance expectancy, effort expectancy, social influence and facilitating conditions on behavioural intention. In other words, the study attempted to find out the components of the UTAUT model which are fundamental for the adoption of robotics in the auditing profession. An empirical test carried out with 85 respondents revealed that both performance expectancy and facilitating conditions had a positive impact on behavioural intention. This finding supports the results of a study by Tiberius and Hirth (2019), which found that experts believe that new technologies will not replace auditors, but will instead provide relief and support in their work. Furthermore, the results reveal that gender and experience do not influence the relationship between the components of the UTAUT model and behavioural intention. As expected, the results show that age plays a role in the relationship between social influence and behavioural intention. This suggests that the younger generation (i.e. below 40) are easily persuaded to use new technology. In other words, young auditors will use robotics if it is generally adopted by the audit firms that they aspire to work for, which is in line with the argument put forward by Lois et al. (2020) that technological advances are indispensable for the establishment of an effective digital auditing system.

It is interesting to note that the responses by auditors and non-auditors on behavioural intention, performance expectancy and social factors were significantly different. This suggests that auditors are more optimistic about the use of technology in the auditing profession than non-auditors. The results support the study's findings conducted by Tang et al. (2017), which found that auditors employ data analytics at different times and for different purposes using tools such as Microsoft Excel, Microsoft Access, ACL and Tableau to perform functions. In support of the arguments by Cooper et al. (2019) and a study by the WEF (2015), a lack of training and skills, a lack of good quality data, and the inadequate investment in robotics technology topped the list of the purported barriers of robotics adoption in auditing. Equally, training, management support, and the time incentive to learn and experiment with technology were mentioned as potential enablers.

\section{Conclusion}

An investigation was done into the nature of the relationship between the UTAUT model (performance expectancy, effort expectancy, social influence, facilitating conditions) and the behavioural intention of auditors to use robotics in auditing. To better understand the nature of the relationship between these constructs, an analysis was done of the differences of opinion between auditors and non-auditors. Furthermore, the analysis was expanded to assess the influence of age, gender and experience on the nature of the relationship between these constructs. From a theoretical perspective, the results of this study highlight the importance of understanding the barriers and the potential enablers of adopting the use of technology in the auditing profession. The study used openended questions to capture the opinion of participants about the possible barriers and enablers. The study found that poor data quality is one of the potential barriers because incorrect data could lead to inaccurate audit outcomes, which may have severe implications for the audited organisation. The results from the study show that performance expectancy and facilitating conditions play a major role in the adoption of robotics in the auditing process. In addition, the study indicates that age may be a factor to consider, particularly from a social influence point of view. A lack of funding and limited skills in technology are mentioned as a possible hurdle in the adoption of robotics adoption in auditing. Training and management support are proposed as potential solutions to this barrier.

The conclusion drawn from the above synthesis is twofold. Firstly, the performance management system and the business case for robotics in the auditing process should be linked to the tasks of auditors, and the infrastructure, environment, culture, and legislation should be conducive to technology adoption in the profession. Secondly, resources should be made available to support the use of technology in the profession, but most importantly, there should be a 
willingness and belief by leadership that technology will improve the effectiveness and efficiency of the auditing activities. Therefore, management is encouraged to consider the strategic direction of their organisation by ensuring that adequate budget is allocated towards skills development, investment in technology, and improved data infrastructure to increase operational efficiency.

\section{Limitations, recommendations and future research}

This study was limited in several ways. Firstly, the sample was 85, which is acceptable for a quantitative study, but presented some limitation in analysing the differences of opinion between auditors and non-auditors $(n<30)$. Secondly, the quantitative approach was mainly used in this study. It emerged that there was a need for a qualitative research to understand better the enablers of and barriers to adopting robotics in the auditing profession. Nevertheless, this study provides a high level of understanding of how professional auditors view the potential impact of robotics technology on the industry.

Further research is required using a larger sample and using a mixed-method (qualitative and quantitative) approach. Future studies should also consider including an acceptable sample size of non-auditors. This study contributes to the academic literature and the industry discussion on how new technologies, such as robotics technology, can enhance the efficiency and the presentational trustworthiness of the audit outcome results and how this new technology will impact the future of the auditing profession. Auditing academics and the industry must be informed about these discussions, considering the interrelated risks associated with the complexity of global markets and the increasing need for a timely and accurate procedure.

\section{Acknowledgements Competing interests}

The authors declare that they have no financial or personal relationship that may have inappropriately influenced them in writing this article.

\section{Author's contributions}

T.S. drafted the article, which is based on the data collected by E.N. on his studies (Master of Digital Business Dissertation). T.S. was the supervisor for E.N.

\section{Ethical considerations}

The low-risk application was reviewed by the Wits University Ethics Review Committee and was approved on 20 June 2020. This study is based on questionnaires with adults.

\section{Funding information}

This research received no specific grant from any funding agencies in public, commercial or not-for-profit sectors.

\section{Data availability}

Data are available from the corresponding author (T.S.) upon request.

\section{Disclaimer}

The views and opinions expressed in this article are those of the authors and do not necessarily reflect the official policy or position of any affiliated agency of the authors.

\section{References}

Ajao, O., Jayeoba, O. \& Ajibade, A., 2016, 'Evolution and development of auditing', Unique Journal of Business Management Research 3, 32-40.

Auditor-General South Africa, 2011, Audit process, accountability and remedies, glossary of terms, acronyms and abbreviations, viewed 13 June 2021, from https://www.agsa.co.za/Portals/O/MFMA2011-12Extracts/MFMA 201112 consolidated_extracts/21_MFMA_2011 12 Audit process_Accountability and remedies_Glossary_of_terms_Acronyms_and_abbreviations.pdf.

Avery, H., 2019, Private banking: Wealthtech 2.0-When human meets robot, viewed 05 April 2020, from https://www.euromoney.com/article/b1cygh7rdnlqk1/ private-banking-wealthtech-20-when-human-meets-robot.

Braun, V. \& Clarke, V., 2006, 'Using thematic analysis in psychology', Qualitative Research in Psychology 3(2), 77-101. https://doi.org/10.1191/1478088706 qp063oa

Cheng, A., 2019, 6 retail tech trends to watch for 2019 that go beyond competing with amazon, viewed 05 April 2020, from https://www.forbes.com/sites/ andriacheng/2019/01/20/six-key-retail-tech-trends-towatch-for-2019-and-itsnot-just-about-amazon

Cooper, L.A., Holderness, D.K., Sorensen, T.L. \& Wood, D.A., 2019, 'Robotic process automation in public accounting', Accounting Horizons 33(4), 15-35. https://doi. org/10.2308/acch-52466

Gotthardt, M., Koivulaakso, D., Paksoy, O., Saramo, C., Martikainen, M. \& Lehner, O., 2020, 'Current state and challenges in the implementation of smart robotic process automation in accounting and auditing',. ACRN Journal of Finance and Risk Perspectives 9(2020), 90-102. https://doi.org/10.35944/jofrp.2020.9.1.007

Gurama, Z.U., Usman, I. \& Murtala, S., 2019, 'Impact of history in determining internal audit effectiveness in tax administration', Sahel Analyst: Journal of Management Sciences 16(6), 55-68.

Harris, S.B., 2017, Technology and the audit of today and tomorrow, viewed 13 June 2021, from https://pcaobus.org/News/Speech/Pages/Harrisstatement-PCAOBAAA-4-20-17.aspx.

Hermanson, D.R., Hermanson, H.M. \& Hermanson, S.D., 2020, 'Where is public company auditing headed?', The CPA Journal 90(2), 54-59.

Huang, F., 2018, Three essays on emerging technologies in accounting, viewed 13 June 2021, from https://rucore.libraries.rutgers.edu/rutgers-lib/59927/.

Hyken, S., 2017, Al and chatbots are transforming the customer experience, viewed 28 May 2020, from https://www.forbes.com/sites/ shephyken/2017/07/15/ai-and-chatbots-are-transforming-the-customerexperience/\#5f09505741f7.

Kokina, J. \& Davenport, T.H., 2019, 'Early evidence of digital labor in accounting: Innovation with robotic process automation', International Journal of Accounting Information Systems 35, 100431. https://doi.org/10.1016/j.accinf.2019.100431

Lacity, M.C. \& Willcocks, L.P., 2016, A new approach to automating services, viewed 15 May 2020, from https://sloanreview.mit.edu/article/a-new-approachto-automating-services/.

Lanfranco, A.R., Castellanos, A., Desai, J.P. \& Meyers, W., 2004, 'Robotic surgery: A current perspective', Annals of Surgery 239, 14-21. https://doi.org/10.1097/01. sla.0000103020.19595.7d

Lay, K., 2019, Robot that's tuned into dementia, viewed 17 April 2020, from https:// www.thetimes.co.uk/article/robot-that-s-tuned-into-dementia-2m83zq67w.

Lois, P., Drogalas, G., Karagiorgos, A. \& Tsikalakis, K., 2020, 'Internal audits in the digital era: Opportunities risks and challenges', EuroMed Journal of Business 15(2), 205-217. https://doi.org/10.1108/EMJB-07-2019-0097

Lombardi, D., Bloch, R. \& Vasarhelyi, M., 2015, 'The current state and future of the audit profession', Current Issues in Auditing 9(1), 10-16. https://doi.org/10.2308/ ciia-50988

Rose, M., Rojhani, E. \& Rodrigues, V., 2018, 'The rise of automation', Internal Auditor 75, 36-40.

Seago, J., 2017, 'Auditing what matters', Internal Auditor 74, 22-27.

Sexton, N. \& Rudman, R., 2019, 'Audit firms to employ a comprehensive approach to keep pace with the evolving information technology control environment', Journa of Accountability and Auditing Research 21(1), 1-13.

Sharma, R., Mithas, S. \& Kankanhalli, A., 2014, 'Transforming decision-making processes: A research agenda for understanding the impact of business analytics on organisations', European Journal of Information Systems 23(4), 433-441. https://doi.org/10.1057/ejis.2014.17 
Syed, R., Suriadi, S., Adams, M., Bandara, W., Leemans, S.J.J., Ouyang, C. et al., 2020, 'Robotic process automation: Contemporary themes and challenges', Computers in Industry 115, 103162. https://doi.org/10.1016/j. compind.2019.103162

Tang, F., Norman, C.S. \& Vendrzyk, V.P., 2017, 'Exploring perceptions of data analytics in the internal audit function', Behaviour \& Information Technology 36(11), 1125-1136. https://doi.org/10.1080/0144929X.2017.1355014

Tiberius, V. \& Hirth, S., 2019, 'Impacts of digitization on auditing: A Delphi study for Germany', Journal of International Accounting, Auditing and Taxation 37, 1020288. https://doi.org/10.1016/j.intaccaudtax.2019.100288
Urban, S., 2017, 'The innovative internal auditor', Internal Auditor, viewed 13 June 2021 , from https://iaonline.theiia.org/2017/Pages/The-Innovative-Internal-Auditor.aspx.

Venkatesh, V., Morris, M.G., Davis, G.B. \& Davis, F.D., 2003, 'User acceptance of information technology: Toward a unified view', MIS Quarterly 27(3), 425-478. https://doi.org/10.2307/30036540

Wang, T. \& Cuthbertson, R., 2015, 'Eight issues on audit data analytics we would like researched', Journal of Information Systems 29(1), 155-162. https://doi. researched', Journal of
org/10.2308/isys-50955

World Economic Forum (WEF), 2015, Deep shift: Technology tipping points and societal impact, viewed 01 June 2020, from http://www3.weforum.org/docs/ WEF_GAC15_Technological_Tipping_Points_report_2015.pdf. 